\title{
O perfil dos produtores de leite, o processo de sucessão e a renda bruta no Rio Grande do Sul: análise do Corede Produção ${ }^{1}$
}

\author{
Ben-hur D. da Rocha Júnior \\ Marco Antonio Montoya* \\ Cássia Aparecida Pasqual **** \\ Eduardo Belisário Finamore ${ }^{* * * * * *}$
}

\section{Resumo}

O artigo busca apresentar o perfil dos produtores de leite do Corede Produção do Rio Grande do Sul, analisar o processo de sucessão da propriedade e estimar a renda bruta dos produtores da matéria-prima leite. Para desvelar esses dados, desenvolveu-se uma pesquisa de campo com uma amostra de 194 produtores de leite. Identificou-se que, em 75,3\% das propriedades, o sistema produtivo mais utilizado é o método a pasto. Os produtores dessa região estão trabalhando na atividade há 19 anos, apresentando um grau de escolaridade médio de sete anos. Nesses casos, o manejo é realizado em 79,9\% pelas esposas, incluindo atividades de gestão da atividade leiteira. Por fim, almeja-se que os indicadores analisados neste artigo sirvam de sustento para decisões que envolvam todas as cadeias produtivas, em específico, a cadeia produtiva láctea, em especial os produtores do Corede Produção, foco deste estudo.

Palavras-chave: Agronegócio. Cadeia láctea. Perfil. Renda. Sucessão.

* Pós-Graduado em MBA em Economia e Gestão Empresarial pela Universidade de Passo Fundo (UPF) 2013. Bacharel em Administração de Empresas pela Universidade de Passo Fundo (UPF).

** Doutor em Economia Aplicada pela Universidade de São Paulo (USP), Mestre em Economia Rural pela Universidade Federal do Rio Grande do Sul (UFRGS). Professor da Faculdade de Ciências Econômicas, Administrativas e Contábeis da Universidade de Passo Fundo (UPF).

*** Mestre em Agronegócios pela Universidade Federal do Rio Grande do Sul (UFRGS). Professora da Faculdade de Ciências Econômicas, Administrativas e Contábeis da Universidade de Passo Fundo (UPF).

**** Doutor em Economia Aplicada pela Universidade Federal de Viçosa (UFV). Professor da Faculdade de Ciências Econômicas, Administrativas e Contábeis da Universidade de Passo Fundo (UPF).

http://dx.doi.org/10.5335/rtee.v20i42.4476

Submissão: 19/12/2013. Aceite: 14/07/2014 


\section{Introdução}

Nos últimos anos, a cadeia produtiva de lácteos do Brasil vem sofrendo mudanças significativas. Hoje, o Brasil está entre os cinco maiores produtores de leite do mundo, com destaque para o estado de Minas Gerais, o maior produtor do país, seguido pelo Rio Grande do Sul. Vários fatores favorecem para a elevação da produção de leite no país, como: ganhos com produtividade, baixo custo com mão de obra, e fixação de preço de referência com elevação, de acordo com a qualidade e o volume. Outro fator que impactou o complexo lácteo foi a desregulamentação do mercado, modificando as normas desse, em particular, com a entrada de novas empresas, possibilitando aos produtores entregarem sua produção pelo melhor preço. Cabe destacar que a produção de leite está entre as seis mais importantes atividades da agricultura brasileira. Um aspecto que alavancou o complexo lácteo é o financeiro, a possibilidade de o pequeno produtor ter renda mensal.

A produção de leite no Rio Grande do Sul é marcada principalmente por ser uma ocupação produtiva secundária, ou seja, é realizada paralelamente com outras ações. Entretanto, essa tem recebido maior atenção, devido a sua regularidade nos rendimentos, tornando-se uma das principais atividades dentro de uma Unidade de Produção Agrícola.

O leite, hoje, é um dos principais elos do agronegócio, pois está presente em quase todos os municípios do Rio Grande do Sul, atendendo, desde o grande até as pequeno produtor, por ser uma atividade de baixa exigência tecnológica e com capacidade de empregar mão de obra familiar a um custo quase zero. Atualmente, uma amostra disso é que a economia gaúcha constitui-se, no país, como segunda maior na produção de leite, contribuindo com pouco mais de $13 \%$ da produção nacional, apresentando, nos últimos anos, os maiores ganhos de produtividade do país. Com base nisso, reforça-se a dimensão deste estudo, que tem como finalidade fomentar os órgãos responsáveis pelo desenvolvimento econômico do Corede Produção.

No Rio Grande do Sul, há uma divisão geoeconômica baseada por Conselho Regional de desenvolvimento (Corede), em que o Corede Produção, região desse estudo, abrange 21 municípios, apresentando-se como uma promissora região produtora de leite, apresentando mais de seis mil e quinhentos estabelecimentos dedicados à produção de leite. Os municípios da região produzem mais de 150 milhões de litros de leite, havendo, inclusive, alguns desses que se destacaram nacionalmente nos últimos anos por apresentarem os maiores níveis de produção e de produtividade de leite do país. A região do Corede Produção, de acordo com a Fundação de Economia e Estatística (FEE) (2011), conta com uma população total de 339.921 
habitantes, com uma área de $6.002,7 \mathrm{~km}^{2}$, totalizando um Produto Interno Bruto (PIB) de R\$ 8.607.218.

Diante desse contexto, surgem questões como: qual é o perfil socioeconômico dos produtores de leite e como está o processo de sucessão familiar na atividade? Qual é a importância econômica da atividade leiteira nas propriedades? Qual é a renda bruta da atividade leiteira por sistema e por estrato de produção? Quem administra a propriedade e como acontece a tomada de decisões? A produção de leite é a principal atividade da propriedade ou é complementar a outras existentes?

Com base nesse levantamento, pretende-se apresentar o perfil do produtor de leite do Corede Produção, analisar os dados que traduzem o processo de sucessão das propriedades, bem como estimar a renda bruta da propriedade, partindo dos produtores agrícolas, com o propósito de servir de custeio para a manutenção das políticas de desenvolvimento do setor e da região, fortalecendo a cadeia produtiva do leite nos municípios e no estado. Logo, tais apontamentos visam investigar alguns aspectos relevantes dos produtores de leite do Rio Grande do Sul no Corede Produção.

Para melhor desenvolver o objetivo, na seção 2, expõe-se, de forma sucinta, o referencial teórico que trata da cadeia produtiva agroindustrial e especificamente da cadeia produtiva láctea; já na seção 3 , apresenta-se o método utilizado na pesquisa. Logo após, serão exibidas as análises e os dados referentes aos produtores de leite do Corede Produção, e, por fim, serão apresentadas as principais conclusões alcançadas no transcorrer das análises.

\section{Referencial teórico}

Nesta seção, apresentam-se as definições de uma cadeia produtiva agroindustrial, independente de qual commodity é utilizada, buscando posteriormente desmistificar a cadeia produtiva láctea.

\subsection{Cadeia produtiva agroindustrial}

O estudo da cadeia produtiva agroindustrial é uma das ferramentas prerrogativas da escola francesa. Um dos estudiosos da área, Morvan (1985) apud Padula et al. (1998), tem a cadeia produtiva agroindustrial como um sistema formado por um conjunto de operações em sequência que norteiam a produção de bens, visto que sua produção está amplamente influenciada pelas possibilidades tecnológicas dos 
elos e também determinando as ações unicamente nas estratégias dos seus atores. Ainda assim, o autor acredita que os elos das cadeias são fontes de informações importantíssimas para o sistema produtivo, desde informações técnicas, relações comerciais, financeiras até experiências de relevância para o crescimento da cadeia.

De acordo com Batalha (2010), existem algumas aplicações do conceito de cadeia produtiva agroindustrial, sendo que uma dessas, "Cadeia de produção como ferramentas de descrição técnico-econômica”, define bem a cadeia produtiva agroindustrial. Consiste em descrever os responsáveis pelas operações e pela produção da transformação da matéria-prima em produto acabado ou semiacabado, uma vez que um elemento que complementa a análise técnica da cadeia produtiva agroindustrial é considerá-la também como uma ferramenta de análise econômica, obtendo assim duas linhas que se completam e determinam bem a ferramenta.

A definição fornecida por Morvan e Batalha prova que qualquer sistema produtivo pode ser visualizado e examinado por meio de uma cadeia, em que é possível identificar a cadeia produtiva baseada em três fatores: a tecnologia, os mercados e os produtos. Todavia, torna-se facilitado o entendimento desse modelo de cadeia produtiva, quando aplicada no Sistema Agroindustrial, por existirem fatores peculiares a ela.

Segundo Araújo (2010), para análise e compreensão de uma cadeia produtiva, é necessário seguir algumas etapas:

a. efetuar a descrição de toda a cadeia de produção;

b. reconhecer o papel da tecnologia como alicerce da cadeia produtiva;

c. organizar estudos e integrações;

d. analisar as políticas voltadas para todo o agronegócio;

e. compreender a matriz de insumo-produto para cada produto agropecuário;

f. apreciar as estratégias das firmas e das associações.

Com a compreensão das funções de uma cadeia produtiva e inter-relações entre os segmentos, existe uma possibilidade maior de êxito nas ações e intervenções dos agentes que dessa participam. Araújo (2010, p. 13) reforça que "O entendimento das inter-relações entre segmentos e agentes de uma cadeia produtiva é tão, ou até mais, importante quanto conhecer a existência dos mesmos", ou seja, ele busca demonstrar a importância de se identificar os elos da cadeia produtiva de forma que não se trate nenhum de forma isolada.

Dentre as diversas cadeias produtivas existentes hoje, a que está em estudo neste artigo é a cadeia produtiva láctea, que será melhor apresentada no próximo item. 


\subsubsection{Cadeia produtiva láctea}

A cadeia produtiva láctea utiliza-se das mesmas técnicas, porém com um direcionamento para a produção de leite. Conforme Montoya e Finamore (2008), 78,28\% dos produtores do Conselho Regional de Desenvolvimento - Noroeste (Corede) afirmam que a pecuária de leite é a principal dentro da unidade de produção agrícola.

O leite é a commodity mais sensível e delicada produzida no campo, principalmente por tratar-se de uma produção que exige dedicação durante todo o ano. A sua comercialização tem grande destaque para a manutenção da qualidade do produto, tendo que ser ágil com a matéria-prima, que, muitas vezes, é coletada na madrugada para entregar ao comprador no início da manhã. Em virtude destas peculiaridades: cuidados higiênicos, disponibilidade de horários, sensibilidade e delicadeza, Montoya e Finamore (2008) afirmam que em 70,83\% das propriedades são as mulheres que executam o manejo do rebanho e o controle de receitas e despesas, uma vez que $23,44 \%$ executam apenas a ordenha.

Dentre os sistemas de produção utilizados pelos produtores de leite, existem três tipos básicos de sistema produtivo: sistemas intensivos (confinado), extensivo (a pasto) e semi-intensivo (semiconfinado).

\subsubsection{Sistema de produção intensivo ou confinado}

Conforme Araújo (2010), o sistema intensivo ou confinado refere-se à criação de animais presos, que se caracteriza pela utilização de tecnologias sofisticadas, consequentemente, de maiores investimentos e de maior dedicação dos trabalhadores. É possível verificar que essa forma de produção é utilizada principalmente por grandes produtores, cujos rendimentos da propriedade vêm da produção de leite, justificando-se os altos investimentos de imobilizado e de mão de obra.

\subsubsection{Sistema de produção extensivo ou a pasto}

Segundo Montoya e Finamore (2008), o sistema extensivo ou a pasto é o sistema em que $50 \%$ da matéria seca advém do pastejo. Esse sistema caracteriza-se pelo uso, ou não, de forragens, conservadas. Porém, para se garantir uma produtividade em níveis elevados, é essencial a utilização de suplementos com alto valor nutritivo. O sistema a pasto diferencia-se do sistema confinado principalmente por não 
exigir um grande número de trabalhadores e investimentos em máquinas e equipamentos. Porém, para um rendimento de 12 a15 kg de leite vaca/dia, é necessário suplementar os animais com forragens de alto valor nutritivo.

\subsubsection{Sistema de produção semi-intensivo ou semiconfinado}

Para Araújo (2010), o sistema semi-intensivo ou semiconfinado é aquela produção em que os animais são criados, em parte do tempo, confinados com disponibilidade de água e de alimentação básica, como, silagem de milho e sorgo dentre outros, sendo levados a pasto em piquetes em determinados momentos do dia. $\mathrm{O}$ pastoreio acontece de forma rotativa e em pequenas áreas, realizado de um a dois dias em cada área.

\section{Metodologia}

Este estudo tem como objetivo apresentar o perfil dos produtores de leite do Corede Produção, analisar os dados que traduzem o processo de sucessão das propriedades e estimar a renda bruta da propriedade. Adotou-se a metodologia de amostragem semiestratificada, probabilística e de população finita, comumente utilizada em pesquisas de opinião pública e de mercado.

O universo da pesquisa foi determinado por município, por estabelecimentos agrícolas com produção de leite e, ainda, por estratos de produção. A amostra foi composta por 194 produtores distribuídos em 21 municípios, abrangendo todos os da região que apresentavam produção de leite, conforme apresentado na Tabela 1. Para a coleta de dados, foram utilizados dados primários, baseados nos questionários aplicados por oito entrevistadores adequadamente capacitados, sendo o produtor entrevistado em sua propriedade, de modo que o entrevistador pudesse avaliar as respostas fornecidas. Para análise dos dados coletados, utilizou-se a técnica estatística descritiva. 
Tabela 1 - Plano amostral Corede Produção

\begin{tabular}{l|c|c|c|c}
\hline \multicolumn{1}{c|}{ Municípios (RS) } & Estabelecimentos & $\begin{array}{c}\text { Leite } \\
(1000 \text { L) }\end{array}$ & $\begin{array}{c}\text { Participação da } \\
\text { produção (\%) }\end{array}$ & $\begin{array}{c}\text { Distribuição } \\
\text { da amostra }\end{array}$ \\
\hline Marau & 850 & 24.132 & $16,00 \%$ & 25 \\
Casca & 742 & 20.535 & $13,60 \%$ & 22 \\
Passo Fundo & 505 & 8.363 & $5,50 \%$ & 15 \\
Ciríaco & 456 & 3.766 & $2,50 \%$ & 13 \\
David Canabarro & 416 & 6.604 & $4,40 \%$ & 12 \\
Vila Maria & 409 & 13.397 & $8,90 \%$ & 12 \\
Coqueiros do Sul & 352 & 7.641 & $5,10 \%$ & 10 \\
Nova Alvorada & 326 & 5.587 & $3,70 \%$ & 10 \\
Santo Antônio do Palma & 312 & 3.671 & $2,40 \%$ & 9 \\
Camargo & 290 & 5.663 & $3,80 \%$ & 8 \\
Pontão & 272 & 11.422 & $7,60 \%$ & 8 \\
Mato Castelhano & 234 & 2.393 & $1,60 \%$ & 7 \\
Almirante Tamandaré do Sul & 230 & 5.815 & $3,50 \%$ & 7 \\
Gentil & 183 & 4.002 & $2,70 \%$ & 5 \\
São Domingos do Sul & 183 & 5.726 & $3,80 \%$ & 5 \\
Ernestina & 160 & 4.683 & $3,10 \%$ & 5 \\
Muliterno & 154 & 3.280 & $2,20 \%$ & 4 \\
Coxilha & 138 & 6.581 & $4,40 \%$ & 4 \\
Santo Antônio do Planalto & 135 & 1.989 & $1,30 \%$ & 4 \\
Carazinho & 130 & 2.845 & $1,90 \%$ & 4 \\
Vanini & 98 & 2.711 & $1,80 \%$ & 3 \\
Questionários Excedentes & 0.575 & 0 & 0 & 194 \\
Total & & 150.796 & $100,00 \%$ & \\
\hline & & & 4 \\
\hline
\end{tabular}

Fonte: Censo Agropecuário, IBGE 2006.

\section{Análise e apreciação dos dados}

Buscando diagnosticar o perfil dos produtores, debater a sucessão da propriedade e estimar a renda bruta dos produtores de leite do Corede Produção, foram coletados dados, por meio de uma pesquisa de campo com uma amostra de 194 produtores de leite. A amostra abrangeu todos os municípios pertencentes ao Corede Produção e foi dividida de acordo com a participação do município na produção de leite, por exemplo: como o município de Marau é o maior produtor com 16\% da 
produção de leite do Corede da Produção, foram entrevistados 25 produtores nesse município, conforme apresentado na Tabela 1.

Para melhor apresentar os dados, foram definidos os dois sistemas de produção mais utilizados no Corede Produção: sistema semiconfinado e sistema a pasto. Buscando expor melhor os dados, as amostras foram divididas em estratos de produção, conforme a distribuição da produção de leite. Com base na pesquisa de campo, na experiência de trabalhos de autores e organizações gaúchas, foram estabelecidos cinco estratos de produção média; primeiro estrato de 0 a 100 litros/dia, segundo de 101 a 200 litros/dia, terceiro estrato de 201 a 350 litros/dia, quarto estrato de 351 a 500 litros/dia e o quinto estrato acima de 500 litros/dia. Nas Tabelas 1.1, 1.2 e 1.3, é possível visualizar a divisão dos estratos de produção e seu sistema produtivo, além da distribuição dos questionários por estrato e sistema produtivo.

Tabela 1.1 - Estrato de produção e sua distribuição na produção de leite

\begin{tabular}{l|c|c|c|c|c|c}
\hline \multirow{2}{*}{ Especificação \% } & \multicolumn{6}{c}{ Estrato produção de leite (litros/dia) } \\
\cline { 2 - 7 } & 0 a 100 & 101 a 200 & 201 a 350 & 351 a 500 & acima de 500 & Total \\
\hline A pasto & $23,2 \%$ & $22,2 \%$ & $17,5 \%$ & $6,7 \%$ & $5,7 \%$ & $75,3 \%$ \\
Semiconfinado & $4,1 \%$ & $6,7 \%$ & $6,7 \%$ & $2,6 \%$ & $4,6 \%$ & $24,7 \%$ \\
Total & $27,3 \%$ & $28,9 \%$ & $24,2 \%$ & $9,3 \%$ & $10,3 \%$ & $100 \%$ \\
\hline
\end{tabular}

Fonte: dados da pesquisa.

Tabela 1.2 - Distribuição dos questionários por estrato de produção

\begin{tabular}{l|c|c|c|c|c|c}
\hline \multirow{2}{*}{ Especificação (anos) } & \multicolumn{6}{c}{ Estrato produção de leite (litros/dia) } \\
\cline { 2 - 7 } & 0 a 100 & 101 a 200 & 201 a 350 & 351 a 500 & acima de 500 & Total \\
\hline A pasto & 45 & 43 & 34 & 13 & 11 & 146 \\
Semiconfinado & 8 & 13 & 13 & 5 & 9 & 48 \\
Total & 53 & 56 & 47 & 18 & 20 & 194 \\
\hline
\end{tabular}

Fonte: dados da pesquisa.

Tabela 1.3 - Distribuição percentual dos questionários por estrato de produção

\begin{tabular}{l|c|c|c|c|c|c}
\hline \multirow{2}{*}{ Especificação \% } & \multicolumn{6}{c}{ Estrato produção de leite (litros/dia) } \\
\cline { 2 - 7 } & 0 a 100 & 101 a 200 & 201 a 350 & 351 a 500 & acima de 500 & Total \\
\hline A pasto & $84,9 \%$ & $76,8 \%$ & $72,3 \%$ & $72,2 \%$ & $55,0 \%$ & $75,3 \%$ \\
Semiconfinado & $15,1 \%$ & $23,2 \%$ & $27,7 \%$ & $27,8 \%$ & $45,0 \%$ & $24,7 \%$ \\
Total & $100 \%$ & $100 \%$ & $100 \%$ & $100 \%$ & $100 \%$ & $100 \%$ \\
\hline
\end{tabular}

Fonte: dados da pesquisa. 
A pesquisa de campo com os produtores foi feita no período de março de 2013 a novembro de 2013. Os dados levantados referem-se ao ano de 2012. Os questionários foram aplicados por um entrevistador adequadamente treinado, e os produtores foram entrevistados em suas propriedades, de modo que pudessem avaliar as respostas fornecidas.

\subsection{Perfil do produtor}

O produtor de leite do Corede Produção tem idade média (Tabela 2) de 49 anos, assemelhando-se a outras regiões do estado e também a outros estados, como Minas Gerais, onde a idade média dos produtores de leite é de 52 anos. Em média, o produtor dessa região está trabalhando na atividade leiteira há 19 anos. O alto índice de permanência do produtor na atividade leiteira deve-se ao elevado capital investido, de baixa liquidez, que mantém o produtor no ramo.

A escolaridade média da região do Corede Produção é de sete anos. O sistema a pasto está apenas dois anos abaixo do sistema semiconfinado (seis anos para o sistema a pasto e oito para o sistema semiconfinado). A escolaridade no campo ainda é baixa, dificultando a implantação de sistemas tecnológicos e de gestão, porém esse índice aumenta à medida que aumentam os estratos de produção e o tipo de sistema de produção utilizado, como é possível verificar nas Tabelas 2.1 e 2.2.

Tabela 2 - Perfil do produtor do Corede Produção

\begin{tabular}{l|c|c|c|c|c|c}
\hline \multirow{2}{*}{ Especificação (anos) } & \multicolumn{7}{c}{ Estrato produção de leite (litros/dia) } \\
\cline { 2 - 7 } & 0 a 100 & 101 a 200 & 201 a 350 & 351 a 500 & acima de 500 & média \\
\hline Idade do produtor & 53 & 49 & 48 & 47 & 45 & 49 \\
Escolaridade & 5 & 7 & 7 & 9 & 10 & 7 \\
Tempo que é produtor & 20 & 20 & 18 & 21 & 19 & 19 \\
\hline
\end{tabular}

Fonte: dados da pesquisa.

Tabela 2.1 - Perfil do produtor no sistema a pasto

\begin{tabular}{l|c|c|c|c|c|c}
\hline \multirow{2}{*}{ Especificação (anos) } & \multicolumn{7}{c}{ Estrato produção de leite (litros/dia) } \\
\cline { 2 - 7 } & 0 a 100 & 101 a 200 & 201 a 350 & 351 a 500 & acima de 500 & média \\
\hline Idade do produtor & 53 & 47 & 47 & 43 & 49 & 49 \\
Escolaridade & 5 & 6 & 7 & 9 & 8 & 6 \\
Tempo que é produtor & 20 & 18 & 20 & 20 & 25 & 20 \\
\hline
\end{tabular}

Fonte: dados da pesquisa. 
Tabela 2.2 - Perfil do produtor no sistema semiconfinado

\begin{tabular}{l|c|c|c|c|c|c}
\hline \multirow{2}{*}{ Especificação (anos) } & \multicolumn{7}{c}{ Estrato produção de leite (litros/dia) } \\
\cline { 2 - 7 } & 0 a 100 & 101 a 200 & 201 a 350 & 351 a 500 & acima de 500 & média \\
\hline Idade do Produtor & 53 & 51 & 50 & 51 & 41 & 49 \\
Escolaridade & 6 & 7 & 7 & 9 & 12 & 8 \\
Tempo que é produtor & 19 & 21 & 17 & 22 & 13 & 18 \\
\hline
\end{tabular}

Fonte: dados da pesquisa.

Quanto à origem do produtor do Corede Produção (Tabela 2.3), em média 76\% são do próprio município, 23,10\% são oriundos de outros municípios, e apenas $0,40 \%$ são provenientes de outros estados. Nas Tabelas 2.4 e 2.5, é possível visualizar a divisão das origens por sistema produtivo, destacando que $29,2 \%$ dos produtores do sistema semiconfinado migraram de suas origens para as localidades, onde, hoje, estão instalados, enquanto $17,1 \%$ do sistema a pasto veio de outras localidades que não o seu município de origem. A Tabela 2.6 reforça a teoria de migração para regiões com maiores facilidades de investimento. Dividindo a produção por estrato e por origem do produtor, percebe-se que, em média, $74,7 \%$ da produção de leite do Corede Produção ainda advêm de produtores do próprio município.

Tabela 2.3 - Origem do produtor do Corede Produção

\begin{tabular}{l|c|c|c|c|c|c}
\hline \multirow{2}{*}{ Especificação \% } & \multicolumn{6}{|c}{ Estrato produção de leite (litros/dia) } \\
\cline { 2 - 7 } & 0 a 100 & 101 a 200 & 201 a 350 & 351 a 500 & acima de 500 & média \\
\hline Próprio município & $68,3 \%$ & $76,8 \%$ & $74,3 \%$ & $66,4 \%$ & $94,4 \%$ & $76,0 \%$ \\
Outro município & $31,7 \%$ & $23,2 \%$ & $24,2 \%$ & $33,6 \%$ & $5,6 \%$ & $23,7 \%$ \\
Outro estado & $0 \%$ & $0 \%$ & $1,5 \%$ & $0 \%$ & $0 \%$ & $0,3 \%$ \\
Total & $100 \%$ & $100 \%$ & $100 \%$ & $100 \%$ & $100 \%$ & $100 \%$ \\
\hline
\end{tabular}

Fonte: dados da pesquisa.

Tabela 2.4 - Origem do produtor no sistema a pasto

\begin{tabular}{l|c|c|c|c|c|c}
\hline \multirow{2}{*}{\multicolumn{1}{c|}{ Especificação \% }} & \multicolumn{7}{c}{ Estrato produção de leite (litros/dia) } \\
\cline { 2 - 7 } & 0 a 100 & 101 a 200 & 201 a 350 & 351 a 500 & acima de 500 & total \\
\hline Próprio município & $86,7 \%$ & $76,7 \%$ & $79,4 \%$ & $72,7 \%$ & $100 \%$ & $82,2 \%$ \\
Outro município & $13,3 \%$ & $23,3 \%$ & $17,6 \%$ & $27,3 \%$ & $0 \%$ & $17,1 \%$ \\
Outro estado & $0 \%$ & $0 \%$ & $2,9 \%$ & $0 \%$ & $0 \%$ & $0,7 \%$ \\
Total & $100 \%$ & $100 \%$ & $100 \%$ & $100 \%$ & $100 \%$ & $100 \%$ \\
\hline
\end{tabular}

Fonte: dados da pesquisa. 
Tabela 2.5 - Origem do produtor no sistema semiconfinado

\begin{tabular}{l|c|c|c|c|c|c|}
\hline \multirow{2}{*}{ Especificação \% } & \multicolumn{7}{c}{ Estrato produção de leite (litros/dia) } \\
\cline { 2 - 7 } & 0 a 100 & 101 a 200 & 201 a 350 & 351 a 500 & acima de 500 & Total \\
\hline Próprio município & $50 \%$ & $76,9 \%$ & $69,2 \%$ & $60 \%$ & $88,9 \%$ & $70,8 \%$ \\
Outro município & $50 \%$ & $23,1 \%$ & $30,8 \%$ & $40 \%$ & $11,1 \%$ & $29,2 \%$ \\
Outro estado & $0 \%$ & $0 \%$ & $0 \%$ & $0 \%$ & $0 \%$ & $0 \%$ \\
Total & $100 \%$ & $100 \%$ & $100 \%$ & $100 \%$ & $100 \%$ & $100 \%$ \\
\hline
\end{tabular}

Fonte: dados da pesquisa.

Tabela 2.6 - Distribuição percentual da produção de leite por origem de produtor

\begin{tabular}{l|c|c|c|c|c|c}
\hline \multirow{2}{*}{ Especificação \% } & \multicolumn{5}{c}{ Estrato rodução de leite (litros/dia) } \\
\cline { 2 - 7 } & 0 a 100 & 101 a 200 & 201 a 350 & 351 a 500 & acima de 500 & Total \\
\hline Próprio município & $18,6 \%$ & $22,2 \%$ & $18,0 \%$ & $6,2 \%$ & $9,7 \%$ & $74,7 \%$ \\
Outro município & $8,7 \%$ & $6,7 \%$ & $5,9 \%$ & $3,1 \%$ & $0,6 \%$ & $25 \%$ \\
Outro estado & $0 \%$ & $0 \%$ & $0,3 \%$ & $0 \%$ & $0 \%$ & $0,3 \%$ \\
Total & $27,3 \%$ & $28,9 \%$ & $24,2 \%$ & $9,3 \%$ & $10,3 \%$ & $100 \%$ \\
\hline
\end{tabular}

Fonte: dados da pesquisa.

Outra característica do produtor de leite do Corede Produção refere-se à sua residência. A grande maioria dos entrevistados (92,7\%) reside na própria empresa rural, conforme apresentado na Tabela 2.7; para uma pequena comparação, segundo pesquisas em Minas Gerais, 77\% dos produtores residem na empresa. A presença do produtor facilita a administração e o controle da propriedade, porém, percebe-se nas Tabelas 2.8 e 2.9 - divididas por sistema produtivo - uma pequena alteração dos dados, conforme aumenta a produtividade e o tipo do sistema produtivo.

Tabela 2.7 - Residência do produtor - mais de 70\% do tempo - Corede Produção

\begin{tabular}{l|c|c|c|c|c|c}
\hline \multirow{2}{*}{ Especificação \% } & \multicolumn{7}{|c}{ Estrato produção de leite (litros/dia) } \\
\cline { 2 - 7 } & 0 a 100 & 101 a 200 & 201 a 350 & 351 a 500 & acima de 500 & média \\
\hline Propriedade rural & $100 \%$ & $97,7 \%$ & $100 \%$ & $86,2 \%$ & $79,8 \%$ & $92,7 \%$ \\
Cidade & $0 \%$ & $2,3 \%$ & $0 \%$ & $13,8 \%$ & $20,2 \%$ & $7,3 \%$ \\
Total & $100 \%$ & $100 \%$ & $100 \%$ & $100 \%$ & $100 \%$ & $100 \%$ \\
\hline
\end{tabular}

Fonte: dados da pesquisa. 
Tabela 2.8 - Residência do produtor - mais de $70 \%$ do tempo - sistema a pasto

\begin{tabular}{l|c|c|c|c|c|c}
\hline \multirow{2}{*}{ Especificação \% } & \multicolumn{7}{|c}{ Estrato produção de leite (litros/dia) } \\
\cline { 2 - 7 } & 0 a 100 & 101 a 200 & 201 a 350 & 351 a 500 & acima de 500 & total \\
\hline Propriedade Rural & $100 \%$ & $95,3 \%$ & $100 \%$ & $92,3 \%$ & $81,8 \%$ & $96,6 \%$ \\
Cidade & $0 \%$ & $4,7 \%$ & $0 \%$ & $7,7 \%$ & $18,2 \%$ & $3,4 \%$ \\
Total & $100 \%$ & $100 \%$ & $100 \%$ & $100 \%$ & $100 \%$ & $100 \%$ \\
\hline
\end{tabular}

Fonte: dados da pesquisa.

Tabela 2.9 - Residência do produtor - mais de $70 \%$ do tempo - sistema semiconfinado

\begin{tabular}{l|c|c|c|c|c|c}
\hline \multirow{2}{*}{ Especificação \% } & \multicolumn{7}{|c}{ Estrato produção de leite (litros/dia) } \\
\cline { 2 - 7 } & 0 a 100 & 101 a 200 & 201 a 350 & 351 a 500 & acima de 500 & total \\
\hline Propriedade Rural & $100 \%$ & $100 \%$ & $100 \%$ & $80 \%$ & $77,8 \%$ & $93,8 \%$ \\
Cidade & $0 \%$ & $0 \%$ & $0 \%$ & $20 \%$ & $22,2 \%$ & $6,2 \%$ \\
Total & $100 \%$ & $100 \%$ & $100 \%$ & $100 \%$ & $100 \%$ & $100 \%$ \\
\hline
\end{tabular}

Fonte: dados da pesquisa.

Os entrevistados tinham em média 1,94 filhos, desses 1,01 eram homens e 0,93 mulheres. Apenas 37,6\% dos filhos homens trabalham na produção de leite, e somente $16,3 \%$ das mulheres ocupam-se desse trabalho, demonstrando que 52,60\% dos filhos e filhas exercem alguma atividade na produção leiteira, e o restante está idealizando sua vida profissional na cidade, conforme exposto na Tabela 2.10. Já nas Tabelas 2.11 e 2.12, observa-se que a estrutura familiar está divida por sistema produtivo. É importante destacar, no sistema semiconfinado, um dado elevado, a saber, 1,09 filhos e filhas estão migrando para a cidade enquanto no sistema a pasto esse número é de 0,80 filhos e filhas, demonstrando que, conforme o sistema produtivo, o êxodo rural é maior, em virtude das tecnologias, da mão de obra contratada e de metodologias de produção. 
Tabela 2.10 - Estrutura familiar do produtor de leite do Corede Produção

\begin{tabular}{l|c|c|c|c|c|c}
\hline \multirow{2}{*}{ Especificação } & \multicolumn{7}{c}{ Estrato produção de leite (litros/dia) } \\
\cline { 2 - 7 } & 0 a 100 & 101 a 200 & 201 a 350 & 351 a 500 & acima de 500 & média \\
\hline Filho menos de 12 anos & 0,09 & 0,21 & 0,21 & 0,18 & 0,15 & 0,17 \\
Filho mais de 12 anos & 1,03 & 0,88 & 0,84 & 0,83 & 0,65 & 0,84 \\
Filho trabalhando na produção de leite & 0,47 & 0,30 & 0,38 & 0,42 & 0,36 & 0,39 \\
Filho trabalhando na cidade & 0,38 & 0,54 & 0,42 & 0,42 & 0,15 & 0,38 \\
Filha menor de 12 anosanosanos & 0,06 & 0,19 & 0,13 & 0,00 & 0,25 & 0,13 \\
Filha maior de 12 anos & 0,77 & 0,71 & 0,67 & 0,87 & 0,97 & 0,80 \\
Filha trabalhando na produção de leite & 0,08 & 0,13 & 0,14 & 0,32 & 0,10 & 0,15 \\
Filha trabalhando na cidade & 0,58 & 0,51 & 0,42 & 0,55 & 0,66 & 0,54 \\
Total de filhos & 1,95 & 1,99 & 1,85 & 1,88 & 2,02 & 1,94 \\
\hline
\end{tabular}

Fonte: dados da pesquisa.

Tabela 2.11 - Estrutura familiar do produtor de leite no sistema a pasto

\begin{tabular}{l|c|c|c|c|c|c}
\hline \multirow{2}{*}{ Especificação } & \multicolumn{7}{c}{ Estrato produção de leite (litros/dia) } \\
\cline { 2 - 7 } & 0 a 100 & 101 a 200 & 201 a 350 & 351 a 500 & acima de 500 & média \\
\hline Filho menor de 12 anos & 0,18 & 0,25 & 0,35 & 0,15 & 0,18 & 0,24 \\
Filho maior de 12 anos & 0,93 & 0,84 & 0,91 & 0,46 & 0,64 & 0,84 \\
Filho trabalhando na produção de leite & 0,31 & 0,29 & 0,53 & 0,23 & 0,27 & 0,34 \\
Filho trabalhando na cidade & 0,51 & 0,47 & 0,38 & 0,23 & 0,18 & 0,42 \\
Filha menor de 12 anos & 0,11 & 0,23 & 0,18 & 0,00 & 0,27 & 0,16 \\
Filha maior de 12 anos & 0,67 & 0,72 & 0,65 & 0,54 & 0,73 & 0,67 \\
Filha trabalhando na produção de leite & 0,16 & 0,19 & 0,21 & 0,23 & 0,09 & 0,18 \\
Filha trabalhando na cidade & 0,40 & 0,40 & 0,29 & 0,31 & 0,55 & 0,38 \\
Total de filhos & 1,89 & 2,04 & 2,09 & 1,15 & 1,82 & 1,91 \\
\hline
\end{tabular}

Fonte: dados da pesquisa. 
Tabela 2.12 - Estrutura familiar do produtor de leite no sistema semiconfinado

\begin{tabular}{l|c|c|c|c|c|c}
\hline \multirow{2}{*}{ Especificação } & \multicolumn{7}{c}{ Estrato produção de leite (litros/dia) } \\
\cline { 2 - 7 } & 0 a 100 & 101 a 200 & 201 a 350 & 351 a 500 & acima de 500 & média \\
\hline Filho menor de 12 anos & 0,00 & 0,15 & 0,08 & 0,20 & 0,11 & 0,10 \\
Filho maior de 12 anos & 1,13 & 0,92 & 0,77 & 1,20 & 0,67 & 0,90 \\
Filho trabalhando na produção de leite & 0,63 & 0,31 & 0,23 & 0,60 & 0,44 & 0,40 \\
Filho trabalhando na cidade & 0,25 & 0,62 & 0,46 & 0,60 & 0,11 & 0,42 \\
Filha menor de 12 anos & 0,00 & 0,15 & 0,08 & 0,00 & 0,22 & 0,10 \\
Filha maior de 12 anos & 0,88 & 0,69 & 0,69 & 1,20 & 1,22 & 0,88 \\
Filha trabalhando na produção de leite & 0,00 & 0,08 & 0,08 & 0,40 & 0,11 & 0,10 \\
Filha trabalhando na cidade & 0,75 & 0,62 & 0,54 & 0,80 & 0,78 & 0,67 \\
Total de Filhos & 2,01 & 1,91 & 1,62 & 2,60 & 2,22 & 1,98 \\
\hline
\end{tabular}

Fonte: dados da pesquisa.

Segundo Gomes (2006), por um lado, a quase totalidade de uso de mão de obra familiar pelos estratos de menor produção contribui para reduzir os custos de produção e, por consequência, para obter menor custo de sobrevivência, constituindo os modelos de produção que mais resistem a uma situação de preço baixo do leite. Por outro, são modelos de baixa capacidade de resposta aos estímulos do mercado, razão pela qual a participação desses na produção total tende a reduzir, visto que os produtores não se preocupam com os custos indiretos, tais como depreciação e juros sobre o capital. A preocupação central, nesse caso, é apenas em ter um salário mensal - uma das fortes razões para não abandonarem a atividade.

Dentro de uma unidade de produção agrícola, a responsabilidade pela manutenção da propriedade abrange toda a família. Todavia, na cadeia produtiva láctea, percebe-se uma participação média (Tabela 2.13 ) de 79,9\% das esposas em alguma atividade da propriedade. Destaca-se que $35,4 \%$ delas ocupam-se somente com a atividade de ordenha, e 44,4\% executam ordenha e as demais atividades, como registro de despesas e receitas e/ou administração da propriedade rural, reforçando, assim, que a ordenha é tratada como uma atividade feminina dentro da propriedade devido às suas peculiaridades. No entanto, é importante mencionar que, ao se comparar o estrato de 201 a 350 litros, no qual a esposa está presente em $89,4 \%$ das atividades e o estrato acima de 500 litros, em que elas estão presentes em 59,5\% das atividades, percebe-se que, com a evolução das tecnologias produtivas e a implantação de sistemas de gestão, a mulher passa a dividir suas atividades com os empregados da propriedade. 
Analisando as Tabelas 2.14 e 2.15, cujos dados foram divididos de acordo com o sistema produtivo, percebe-se que as proporções das atividades executadas pela esposa sofrem uma variação de apenas $3 \%$ para menos, comparando-se o percentual encontrado no sistema a pasto e no sistema confinado. Esses dados reforçam que o envolvimento da esposa na atividade é visto com bons olhos, pois ela contribui para a redução dos custos de produção, tendo em vista que o custo de oportunidade dessa mão de obra é quase zero.

Tabela 2.13 - Frequência em que a esposa executa alguma atividade

\begin{tabular}{|c|c|c|c|c|c|c|}
\hline \multirow{2}{*}{ Especificação \% } & \multicolumn{6}{|c|}{ Estrato produção de leite (litros/dia) } \\
\hline & 0 a 100 & 101 a 200 & 201 a 350 & 351 a 500 & acima de 500 & média \\
\hline Ordenha & $46,1 \%$ & $29,3 \%$ & $36,9 \%$ & $35,4 \%$ & $29,3 \%$ & $35,4 \%$ \\
\hline Registro de Despesas e Receitas & $0 \%$ & $0 \%$ & $0 \%$ & $0 \%$ & $4,5 \%$ & $0,9 \%$ \\
\hline Administração da Propriedade Rural & $0 \%$ & $0 \%$ & $0 \%$ & $0 \%$ & $4,5 \%$ & $0,9 \%$ \\
\hline $\begin{array}{l}\text { Ordenha e Registro de despesas e } \\
\text { receitas }\end{array}$ & $3,3 \%$ & $10 \%$ & $5,3 \%$ & $0,0 \%$ & $0,0 \%$ & $3,7 \%$ \\
\hline $\begin{array}{l}\text { Ordenha e administração da } \\
\text { propriedade rural }\end{array}$ & $6,7 \%$ & $20,5 \%$ & $23,3 \%$ & $13,8 \%$ & $10,1 \%$ & $14,9 \%$ \\
\hline $\begin{array}{l}\text { Ordenha, Registro de receitas } \\
\text { e despesas e administração da } \\
\text { propriedade }\end{array}$ & $38,3 \%$ & $25,5 \%$ & $23,9 \%$ & $21,5 \%$ & $11,1 \%$ & $24,1 \%$ \\
\hline
\end{tabular}

Fonte: dados da pesquisa.

Tabela 2.14 - Frequência em que a esposa executa alguma atividade - sistema a pasto

\begin{tabular}{|c|c|c|c|c|c|c|}
\hline \multirow{2}{*}{ Especificação \% } & \multicolumn{6}{|c|}{ Estrato produção de leite (litros/dia) } \\
\hline & 0 a 100 & 101 a 200 & 201 a 350 & 351 a 500 & acima de 500 & total \\
\hline Ordenha & $42,2 \%$ & $27,9 \%$ & $35,3 \%$ & $30,8 \%$ & $36,4 \%$ & $34,9 \%$ \\
\hline Registro de despesas e Receitas & $0 \%$ & $0 \%$ & $0 \%$ & $0 \%$ & $9,1 \%$ & $0,7 \%$ \\
\hline Administração da propriedade rural & $0 \%$ & $0 \%$ & $0 \%$ & $0 \%$ & $9,1 \%$ & $0,7 \%$ \\
\hline $\begin{array}{l}\text { Ordenha e registro de despesas e } \\
\text { receitas }\end{array}$ & $6,7 \%$ & $4,7 \%$ & $2,9 \%$ & $0 \%$ & $0 \%$ & $4,1 \%$ \\
\hline $\begin{array}{l}\text { Ordenha e administração da } \\
\text { propriedade rural }\end{array}$ & $13,3 \%$ & $25,6 \%$ & $23,5 \%$ & $7,7 \%$ & $9,1 \%$ & $18,5 \%$ \\
\hline $\begin{array}{l}\text { Ordenha, registro de receitas e } \\
\text { despesas e administração da } \\
\text { propriedade }\end{array}$ & $26,7 \%$ & $27,9 \%$ & $32,4 \%$ & $23,1 \%$ & $0 \%$ & $26,0 \%$ \\
\hline
\end{tabular}

Fonte: dados da pesquisa. 
Tabela 2.15 - Frequência em que a esposa executa alguma atividade - sistema semiconfinado

\begin{tabular}{l|c|c|c|c|c|c}
\hline \multirow{2}{*}{ Especificação \% } & \multicolumn{7}{c}{ Estrato produção de leite (litros/dia) } \\
\cline { 2 - 7 } & 0 a 100 & 101 a 200 & 201 a 350 & 351 a 500 & acima de 500 & total \\
\hline Ordenha & $50 \% \%$ & $30,8 \%$ & $38,5 \%$ & $40 \%$ & $22,2 \%$ & $35,4 \%$ \\
Registro de despesas e receitas & $0 \%$ & $0 \%$ & $0 \%$ & $0 \%$ & $0 \%$ & $0 \%$ \\
Administração da propriedade rural & $0 \%$ & $0 \%$ & $0 \%$ & $0 \%$ & $0 \%$ & $0 \%$ \\
$\begin{array}{l}\text { Ordenha e registro de despesas e } \\
\text { receitas }\end{array}$ & $0 \%$ & $15,4 \%$ & $7,7 \%$ & $0 \%$ & $0,0 \%$ & $6,3 \%$ \\
$\begin{array}{l}\text { Ordenha e administração da } \\
\text { propriedade rural }\end{array}$ & $0 \%$ & $15,4 \%$ & $23,1 \%$ & $20 \%$ & $11,1 \%$ & $14,6 \%$ \\
$\begin{array}{l}\text { Ordenha, registro de receitas e } \\
\text { despesas e administração da } \\
\text { propriedade }\end{array}$ & $50 \%$ & $23,1 \%$ & $15,4 \%$ & $20 \%$ & $22,2 \%$ & $25 \%$ \\
\hline
\end{tabular}

Fonte: dados da pesquisa.

Quando questionados qual a atividade mais importante do ponto de vista econômico (Tabela 2.16), 76,6\% dos produtores do Corede Produção afirmaram que a pecuária de leite é, hoje, a principal fonte de renda da propriedade, sendo seguida de longe por culturas anuais. Conforme aumenta a produção de leite, tais culturas ficam cada vez menos expressivas, fazem do leite a única fonte de renda da propriedade. Um dos principais fatores que tornam a pecuária de leite a principal atividade dentro da propriedade é o fato de essa possibilitar uma renda mensal garantida, conforme já mencionado. Outro fator é o valor bruto por área que se comparado a outras culturas como soja, milho, trigo é bastante atrativo. Vale também destacar que a atividade leiteira no Corede Produção é favorecida pelas condições edafoclimáticas, que dizem respeito às condições de clima e solo, apresentadas na região.

Tabela 2.16 - Opinião dos entrevistados a respeito da atividade mais importante do ponto de vista econômico - Corede Produção

\begin{tabular}{l|c|c|c|c|c|c}
\hline \multirow{2}{*}{\multicolumn{1}{c|}{ Especificação \% }} & \multicolumn{7}{c}{ Estrato produção de leite (litros/dia) } \\
\cline { 2 - 7 } & 0 a 100 & 101 a 200 & 201 a 350 & 351 a 500 & acima de 500 & média \\
\hline Pecuária de leite & $64,2 \%$ & $63,3 \%$ & $63,1 \%$ & $92,4 \%$ & $100 \%$ & $76,6 \%$ \\
Pecuária de corte & $2,2 \%$ & $0 \%$ & $1,5 \%$ & $0 \%$ & $0 \%$ & $0,7 \%$ \\
Outras criações & $2,2 \%$ & $4,7 \%$ & $0 \%$ & $3,8 \%$ & $0 \%$ & $2,1 \%$ \\
Culturas permanentes & $5,6 \%$ & $6,1 \%$ & $12,1 \%$ & $0,0 \%$ & $0 \%$ & $4,8 \%$ \\
Culturas anuais & $22,5 \%$ & $25,9 \%$ & $23,3 \%$ & $3,8 \%$ & $0 \%$ & $15,1 \%$ \\
Fora da propriedade rural & $3,3 \%$ & $0 \%$ & $0 \%$ & $0 \%$ & $0 \%$ & $0,7 \%$ \\
Total & $100 \%$ & $100 \%$ & $100 \%$ & $100 \%$ & $100 \%$ & $100 \%$ \\
\hline
\end{tabular}

Fonte: dados da pesquisa. 
Nas Tabelas 2.17 e 2.18, os dados foram divididos por sistema produtivo, buscando uma melhor visualização da opinião do produtor quanto às atividades da propriedade. Comparando os dados das tabelas, é possível afirmar que o produtor do sistema semiconfinado está confiante de que a cadeia láctea possibilita segurança do ponto de vista econômico, pois $75 \%$ dos produtores focam apenas na produção de leite. Já os produtores do sistema a pasto investem quase $10 \%$ a menos $(65,8 \%)$ na produção leiteira, dividindo o restante em outras criações - pecuária de corte, cultura permanente ou anual e investimentos fora da propriedade rural.

Tabela 2.17 - Opinião dos entrevistados a respeito da atividade mais importante do ponto de vista econômico - sistema a pasto

\begin{tabular}{l|c|c|c|c|c|c}
\hline \multirow{2}{*}{\multicolumn{1}{c|}{ Especificação \% }} & \multicolumn{7}{c}{ Estrato produção de leite (litros/dia) } \\
\cline { 2 - 7 } & 0 a 100 & 101 a 200 & 201 a 350 & 351 a 500 & acima de 500 & total \\
\hline Pecuária de leite & $53,3 \%$ & $65,1 \%$ & $64,7 \%$ & $84,6 \%$ & $100 \%$ & $65,8 \%$ \\
Pecuária de corte & $4,4 \%$ & $0 \%$ & $2,9 \%$ & $0 \%$ & $0 \%$ & $2,1 \%$ \\
Outras criações & $4,4 \%$ & $9,3 \%$ & $0 \%$ & $7,7 \%$ & $0 \%$ & $4,8 \%$ \\
Culturas permanentes & $11,1 \%$ & $4,6 \%$ & $8,8 \%$ & $0 \%$ & $0 \%$ & $6,7 \%$ \\
Culturas anuais & $20 \%$ & $21,0 \%$ & $23,5 \%$ & $7,7 \%$ & $0 \%$ & $18,5 \%$ \\
Fora da propriedade rural & $6,7 \%$ & $0 \%$ & $0 \%$ & $0 \%$ & $0 \%$ & $2,1 \%$ \\
Total & $100 \%$ & $100 \%$ & $100 \%$ & $100 \%$ & $100 \%$ & $100 \%$ \\
\hline
\end{tabular}

Fonte: dados da pesquisa.

Tabela 2.18 - Opinião dos entrevistados a respeito da atividade mais importante do ponto de vista econômico - sistema semiconfinado

\begin{tabular}{l|c|c|c|c|c|c}
\hline \multirow{2}{*}{ Especificação \% } & \multicolumn{7}{c}{ Estrato produção de leite (litros/dia) } \\
\cline { 2 - 7 } & 0 a 100 & 101 a 200 & 201 a 350 & 351 a 500 & acima de 500 & total \\
\hline Pecuária de leite & $75 \%$ & $61,5 \%$ & $61,5 \%$ & $100 \%$ & $100 \%$ & $75,0 \%$ \\
Pecuária de corte & $0 \%$ & $0 \%$ & $0 \%$ & $0 \%$ & $0 \%$ & $0 \%$ \\
Outras criações & $0 \%$ & $0 \%$ & $0 \%$ & $0 \%$ & $0 \%$ & $0 \%$ \\
Culturas permanentes & $0 \%$ & $7,7 \%$ & $15,4 \%$ & $0 \%$ & $0 \%$ & $6,2 \%$ \\
Culturas anuais & $25 \%$ & $30,8 \%$ & $23,1 \%$ & $0 \%$ & $0 \%$ & $18,8 \%$ \\
Fora da propriedade rural & $0 \%$ & $0 \%$ & $0 \%$ & $0 \%$ & $0 \%$ & $0 \%$ \\
Total & $100 \%$ & $100 \%$ & $100 \%$ & $100 \%$ & $100 \%$ & $100 \%$ \\
\hline
\end{tabular}

Fonte: dados da pesquisa. 


\subsection{Processo de sucessão}

Quando os produtores se viram questionados a respeito do processo de sucessão na produção de leite, observou-se na Tabela 3 que 39,2\% dos produtores do Corede Produção acreditam que os filhos continuarão com o gado de leite. No entanto, $28,2 \%$ pensam que os filhos deixarão o meio rural, rumando para a cidade, e 18,5\% que trocarão de atividade ou que venderão a propriedade. Já quando a amostra é dividia por sistema produtivo, visualizam-se poucas alterações nos dados, visto que o único que sofre uma alteração mais relevante é no sistema a pasto, em que 13\% dos entrevistados apontaram que os filhos venderão a propriedade, enquanto no sistema semiconfinado, esse dado cai para $8,6 \%$, muito em virtude dos altos investimentos e dos maiores rendimentos da propriedade e a sua organização dentro do sistema semiconfinado.

Tabela 3 - Opinião dos produtores quanto à sucessão na produção de leite - Corede Produção

\begin{tabular}{l|c|c|c|c|c|c|}
\hline \multirow{2}{*}{\multicolumn{1}{c|}{ Especificação \% }} & \multicolumn{7}{c}{ Estrato produção de leite (litros/dia) } \\
\cline { 2 - 7 } & 0 a 100 & 101 a 200 & 201 a 350 & 351 a 500 & acima de 500 & média \\
\hline Filhos continuarão com o gado de leite & $45 \%$ & $36,3 \%$ & $37,4 \%$ & $31,5 \%$ & $46 \%$ & $39,2 \%$ \\
Filhos trocarão de atividade rural & $5,6 \%$ & $12,3 \%$ & $5,9 \%$ & $10 \%$ & $15,7 \%$ & $9,9 \%$ \\
Filhos deixarão o meio rural & $21,4 \%$ & $29,7 \%$ & $36,3 \%$ & $35,4 \%$ & $18,2 \%$ & $28,2 \%$ \\
Filhos venderão a propriedade & $23,6 \%$ & $9,7 \%$ & $9,7 \%$ & $0 \%$ & $0 \%$ & $8,6 \%$ \\
\hline
\end{tabular}

Fonte: dados da pesquisa.

Observou-se também, nas Tabelas 3.1 e 3.2 que quando os dados são analisados de forma separada, por tipo de produção, existe, na opinião dos produtores, uma tendência, mesmo que pequena, de que em média $13 \%$ dos filhos do sistema a pasto vendam a propriedade. Já os filhos dos produtores nos estratos de 101 a 200, 201 a 350 e 351 a 500 litros por dia tendem a deixar o meio rural. Esse índice é maior nesses três estratos, pois são os que possivelmente utilizam mão de obra contratada, fato que não acontece no estrato de 0 a 100 litros/dia. Por esse e outros motivos, os filhos deixam o meio rural buscando profissionalizar-se, a fim de tentarem a vida na cidade ou, futuramente, retornarem à propriedade e nessa aplicarem o conhecimento adquirido. 
Tabela 3.1 - Opinião dos produtores quanto à sucessão na produção de leite - sistema a pasto

\begin{tabular}{l|c|c|c|c|c|c}
\hline \multirow{2}{*}{\multicolumn{1}{c|}{ Especificação \% }} & \multicolumn{6}{c}{ Estrato produção de leite (litros/dia) } \\
\cline { 2 - 7 } & 0 a 100 & 101 a 200 & 201 a 350 & 351 a 500 & acima de 500 & total \\
\hline Filhos continuarão com o Gado de Leite & $40 \%$ & $41,9 \%$ & $44,1 \%$ & $23,1 \%$ & $36,4 \%$ & $39,7 \%$ \\
Filhos trocarão de atividade rural & $11,1 \%$ & $9,3 \%$ & $11,8 \%$ & $0 \%$ & $9,1 \%$ & $9,6 \%$ \\
Filhos deixarão o meio rural & $17,8 \%$ & $20,9 \%$ & $26,5 \%$ & $30,8 \%$ & $36,4 \%$ & $23,3 \%$ \\
Filhos venderão a propriedade & $22,2 \%$ & $11,6 \%$ & $11,8 \%$ & $0 \%$ & $0 \%$ & $13 \%$ \\
\hline
\end{tabular}

Fonte: dados da pesquisa.

Tabela 3.2 - Opinião dos produtores quanto à sucessão na produção de leite - sistema semiconfinado

\begin{tabular}{l|c|c|c|c|c|c}
\hline \multirow{2}{*}{\multicolumn{1}{c|}{ Especificação \% }} & \multicolumn{5}{c}{ Estrato produção de leite (litros/dia) } \\
\cline { 2 - 7 } & 0 a 100 & 101 a 200 & 201 a 350 & 351 a 500 & acima de 500 & total \\
\hline Filhos continuarão com o gado de leite & $50 \%$ & $30,8 \%$ & $30,8 \%$ & $40 \%$ & $55,6 \%$ & $39,6 \%$ \\
Filhos trocarão de atividade rural & $0 \%$ & $15,4 \%$ & $0 \%$ & $20 \%$ & $22,2 \%$ & $10,4 \%$ \\
Filhos deixarão o meio rural & $25 \%$ & $38,5 \%$ & $46,2 \%$ & $40,0 \%$ & $0 \%$ & $31,3 \%$ \\
Filhos venderão a propriedade & $25 \%$ & $7,7 \%$ & $7,7 \%$ & $0 \%$ & $0 \%$ & $8,3 \%$ \\
\hline
\end{tabular}

Fonte: dados da pesquisa.

\subsection{Renda bruta da produção}

Buscando medir a renda bruta dos produtores do Corede Produção, foram analisados dados capazes de mensurar a produção média por estrato e os rendimentos, ou seja, a renda bruta dos produtores do Corede Produção. Conforme apresentado na Figura 1, os produtores em média produzem 127.120,50 litros de leite ao ano, variando do menor estrato de 0 a 100 litros com uma produção média de 25.908,10 litros de leite/ano, aos produtores do estrato acima de 500 litros que produzem em média 493.969,70 litros de leite/ano. O preço médio unitário pago ao pequeno produtor por litro de leite é de $\mathrm{R} \$ 0,729$, enquanto o produtor acima de 500 litros recebe em média $\mathrm{R} \$ 0,834$, apresentando, assim. uma diferença de $12,60 \%$ nos preços praticados.

Já nas Figuras 2 e 3 em que a renda bruta da produção está dividida por sistema produtivo é possível verificar que a produção de leite média no sistema semiconfinado é mais elevada, alcançando 166.725,20 litros/ano, enquanto a média do 
sistema a pasto é de 87.515,90 litros ao ano, demonstrando, assim, que o sistema semiconfinado demanda maiores investimentos, porém o retorno é visível, pois reflete em uma produção em média $48 \%$ mais elevada. O preço por litro de leite pago aos produtores oscila entre os sistemas de produção, o que se pode verificar nos preços exercidos no estrato de 0 a 100 litros. No sistema a pasto, o valor pago em média por litro de leite é de $\mathrm{R} \$ 0,702$, enquanto o produtor do sistema semiconfinado recebe em média $R \$ 0,756$ por litro de leite - uma diferença de 7,14\% por litro de leite. Vale salientar que a diferença nos preços praticados ocorre em quase todos os estratos, havendo preços equiparados apenas no estrato acima de 500 litros.

Para analisar a renda bruta do Corede Produção, foi necessário mapear outras formas de renda que circundam a produção de leite: leite utilizado para autoconsumo, tanto animal quanto humano, os laticínios vendidos e os laticínios produzidos para consumo próprio, além do consumo dos animais da propriedade. A partir desse levantamento, observou-se que a renda média da região é em torno de $\mathrm{R} \$$ 113.479,33. A renda bruta média do sistema semiconfinado é de $\mathrm{R} \$ 150.056,97$, $52,25 \%$ superior à renda bruta média dos produtores do sistema a pasto. Um dos motivos para essa diferença é a existência de preços distintos para cada tipo de sistema produtivo, ainda que apresentem o mesmo volume de produção, isso se justifica pelo investimento maior dispendido pelo produtor do sistema semiconfinado e por um controle maior do seu rebanho. O reflexo disso é a desmotivação do pequeno produtor do sistema a pasto em investir para aumentar ou melhorar a produção de leite. 

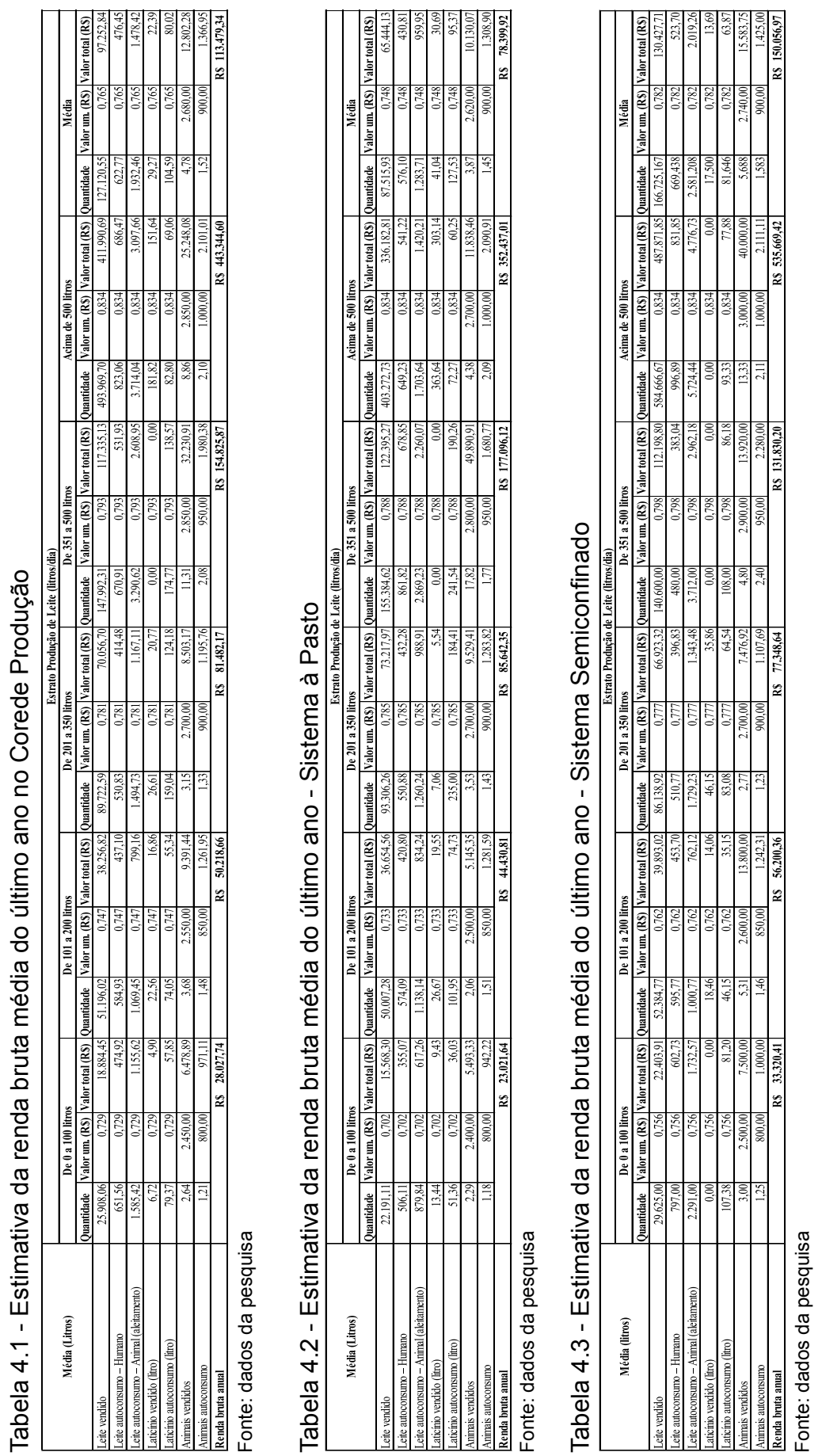

Teoria e Evidência Econômica - Ano 20, n. 42, p. 42-66, jan./jun. 2014 


\section{Considerações finais}

O objetivo deste artigo foi apresentar o perfil do segmento de produtores da cadeia leiteira do Corede Produção, analisar o processo de sucessão da propriedade, bem como estimar sua renda bruta. Constatou-se, a partir da amostra de 194 produtores de leite, que o sistema produtivo mais adotado na região da produção é o sistema a pasto que contempla $75,3 \%$ dos produtores da região, por se tratar do sistema que demanda menos infraestrutura e investimentos. Enquanto isso, 24,7\% dos produtores, em média, praticam o sistema semiconfinado, sistema que necessita de maiores investimentos, apresentando, porém uma produtividade maior. Cabe destacar que $50 \%$ da produção do Corede concentram-se nos pequenos produtores, os quais produzem entre 0 e 200 litros ao dia.

Verificou-se que o produtor dessa região tem idade média de 49 anos, dado que se aproxima dos resultados de outras regiões do estado. Esse produtor, e em média, está trabalhando na atividade há 19 anos, tem escolaridade média baixa, apenas sete anos, o que, muitas vezes, inviabiliza o crescimento da propriedade, dificultando a instalação de sistemas produtivos mais tecnológicos na propriedade e também a implantação de sistemas de gestão e de controle.A atividade de administração da propriedade, de controle de despesas, de receitas e também a prática da ordenha é exercida pelas esposas dos produtores em um índice de, em média, 79,9\% dos casos, o que objetiva a redução dos custos de produção, por tratar-se de uma mão de obra com um custo de oportunidade próximo a zero.

Ao questioná-los quanto à origem, verificou-se que, em média, 76,50\% dos produtores do Corede Produção pertencem àquele município, ou seja, as propriedades vêm passando de geração em geração. Outra característica é que, em média, $92,70 \%$ dos produtores concentram mais de $70 \%$ do tempo em suas propriedades, tornando mais fácil o controle do rebanho e da produção. Os dados não alcançam 100\% dos entrevistados somente porque, conforme aumenta a produtividade, alguns produtores migram para a cidade em busca de mais conforto, motivados, também, por terem empregados para executarem as atividades básicas da propriedade.

Com a finalidade de visualizar a estrutura familiar, verificou-se que os produtores do Corede Produção têm em média 1,94 filhos, sendo 1,01 homens. Desses, apenas $38,61 \%$ trabalham na produção de leite, os demais trabalham na cidade, ou não trabalham. Já as mulheres que correspondem a $0,93 \%$, somente $16,13 \%$ trabalham na produção de leite. Em contrapartida, $58 \%$ delas trabalham na cidade. Esses dados demonstram que uma fatia considerável dos filhos não permanece na propriedade, buscando na cidade o sustento ou até mesmo visando o aperfeiçoando, para, quem sabe, retornar e melhorar a produção. 
Questionados a respeito de qual a atividade de maior importância do ponto de vista econômico, em média, 76,6\% dos produtores afirmaram que a pecuária de leite é, atualmente, a mais importante para a economia do produtor. Esses dados devem-se principalmente à renda mensal advinda da produção de leite, estando acima inclusive de outras culturas sazonais. Outro fator é a exploração da mão de obra familiar, por ser considerada uma atividade de baixo risco, apesar de em produções de pequenas escalas, não ser considerado um negócio lucrativo.

Quanto ao processo de sucessão na manutenção da produção de leite, 39,2\% dos produtores confiam que os filhos continuarão com o gado de leite, perpetuando a família na atividade. Já $28,2 \%$ admitem que os filhos deixarão o meio rural em busca de vida nova na cidade e $18,5 \%$ crê que os descendentes trocarão de atividade ou venderão a propriedade. Analisando os dados simultaneamente, esses insinuam que, quanto menos investimento na produção, menor a produção, acarretando uma rentabilidade inferior, o que torna o processo de sucessão improvável.

Com o intuito de estimar uma renda bruta média para os produtores do Corede Produção e identificar as variações existentes entre os sistemas produtivos, percebeu-se uma expressiva parcela de pequenos produtores (0 a 100 litros/dia) que sofrem com os preços baixos, chegando a $8,24 \%$ abaixo do preço médio praticado no Corede. Outro fator, além do preço, é a falta de incentivos para a produção de leite, com créditos rurais com taxas mais atrativas para esses pequenos produtores aumentarem a sua produtividade. Cabe destacar a inexpressiva parcela de grandes produtores que chegam a uma renda bruta média de $\mathrm{R} \$ 535.669,42$; são produtores que se destacam na região pelos altos investimentos em infraestrutura e pela capacitação dos profissionais envolvidos.

Em síntese, pode-se comprovar que os indicadores apresentados e analisados neste artigo oportunizam visualizar quais são as particularidades dos produtores do Corede Produção, servindo como base para tomada de decisões que visem a melhorar as condições de trabalho dos produtores, proporcionando avanços na produtividade e na qualidade de vida, fazendo com que o produtor permaneça na produção de leite e que busque mais investimentos com a finalidade de aumentar os índices de produtividade do Corede Produção no Rio Grande do Sul. 


\title{
Profile of milk producers, the succession process and gross income in Rio Grande do Sul: analysis of Production Corede
}

\begin{abstract}
The Article seeks to present the profile of the milk producers of Corede Production of Rio Grande do Sul, analyzing the process of succession of property and estimate the gross income of the producers of the raw material milk. To raise these data has developed a field survey with a sample of 194 milk producers. It was identified that in $75.3 \%$ of the properties the productive system is the most used method A Pasture. The producer of this region is working in this activity for 19 years with a degree of schooling average of 7 years, and the management is realized in $79.9 \%$ by wives, including activities for the management of the activity. Finally aims that the indicators analyzed in this article serve as a support for decisions that involve all the productive chains, in particular the productive chain, in particular milk producers of Corede Production focus of this work.
\end{abstract}

Keywords: Agribusiness. Milkmaid chain. Profile. Income. Succession.

\section{Perfil de productores de leche, el proceso de sucesión y la renta bruta en Rio Grande do Sul: análisis de Coredes Producción}

\section{Resumen}

El artículo pretende estabelecer un perfil de los productores de leche del COREDES Producción de Rio Grande do Sul, analizar el proceso de los bienes de la sucesión y estimar el ingreso bruto de los productores de leche cruda. Para recopilar estos datos, se desarrolló un estudio de campo con una muestra de 194 productores de leche. Se encontró que $75,3 \%$ de las propiedades en el sistema de producción es el método más utilizado El Pasto. El productor de esta región están trabajando en la actividad durante 19 años con un grado promedio de 7 años de escolaridad y la gestión que se realiza en el 79,9\% por las mujeres, incluida la gestión de las actividades agrícolas lácteos. Por último, el objetivo es que los indicadores analizados en este artículo sirven de sustento para las decisiones que involucran todas las cadenas de suministro, en particular, la cadena de suministro de productos lácteos, en particular los productores de enfoque COREDES La producción de este trabajo.

Palabras clave: Agronegocios. Cadena láctea. Perfil. Ingresos. Sucesión. 


\section{Nota}

1 Artigo produzido com base no Projeto de Pesquisa da Fundação de Amparo à Pesquisa do Estado do Rio Grande do Sul (Fapergs): “Diagnóstico da produção de leite da região do Corede Produção" - 2012.

\section{Referências}

ARAÚJO, Massilon J. Fundamentos de agronegócios. São Paulo: Atlas, 2010.

BATALHA, Mário Otávio (Coord.). Gestão agroindustrial. São Paulo: Atlas, 2011.

CENTRO DE PESQUISA E EXTENSÃO DA FACULDADE DE CIÊNCIAS ECONÔMICAS, ADMINISTRATIVAS E CONTÁBEIS. Diagnóstico da produção de leite da região do Corede Produção. Passo Fundo: Ed. Universidade de Passo Fundo, 2012, $15 \mathrm{f}$.

FEE - FUNDAÇÃO DE ECONOMIA E ESTATÍSTICA. Corede Produção. Disponível em: <http:// www.fee.tche.br/sitefee/pt/content/resumo/pg_coredes_detalhe.php?corede=Produ\%E7\%E3o $>$. Acesso em: 26 set. 2013.

FINAMORE, E. B. M. de C.; MONTOYA, M. A. Estrutura produtiva da cadeia láctea gaúcha: perspectiva regional do Corede Nordeste. Passo Fundo: Ed. Universidade de Passo Fundo, 2008.

GOMES, S. T. Diagnóstico da pecuária leiteira do estado de Minas Gerais em 2005. Belo Horizonte: Ocemg/Senar, 2006.

INSTITUTO BRASILEIRO DE GEOGRAFIA E ESTATÍSTICA. Censo Agropecuário 2006. Disponível em: <http://www.ibge.gov.br/home/estatistica/economia/agropecuaria/censoagro/default. shtm>. Acesso em: 26 set. 2013.

MONTOYA, M. A.; FINAMORE, E. B. M. de C. Performance e dimensão econômica do complexo lácteo gaúcho. Textos para discussão Universidade de Passo Fundo, n. 3, p. 1-18, jun. 2004.

PADULA, A. D.; et al. A cadeira de suprimentos no setor agroindustrial leiteiro no Rio Grande do Sul: uma análise das estratégias frente ao Mercosul. Porto Alegre: Editora da UFGRS, 1998. 